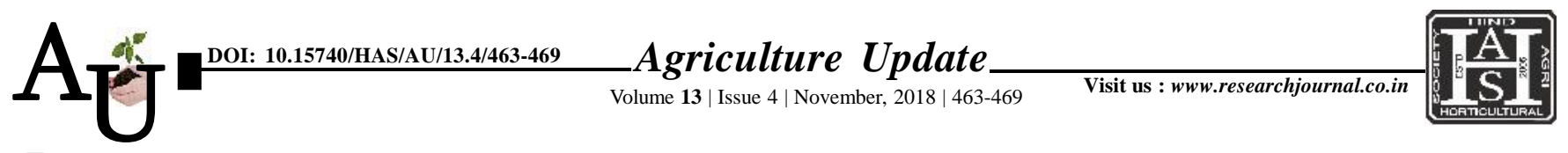

ISSN-0973-1520

A Review:

\title{
Peste des Petits Ruminants in India: A review of economic losses
}

Article Chronicle:

Received :

08.09.2018;

Accepted :

22.10.2018

\section{KEY WoRds:}

Economic loss, Morbidity, Mortality, Peste des petits ruminants, Small ruminants
Author for correspondence :

\section{Rakesh Roy}

Darjeeling Krishi Vigyan Kendra (U.B.K.V.), Kalimpong (W.B.) India Email:rakeshvetext@ gmail.com
SUMMARY : Small ruminants contribute a significant source of supplementary income to the poor rural people but this sector is highly affected due to high incidence of different diseases. Peste des petits ruminants (PPR) is one of the major diseases of small ruminants which is having high incidence rate, morbidity and mortality rate in India. The literature related to economic losses due to PPR has been carefully reviewed and presented in this paper. Various researchers had estimated the economic loss of PPR due to its mortality and morbidity and found it to be high; still they felt many of the incidence, morbidity and mortality in small ruminants might have not been reported. The reviews of various papers and reports had also clearly pointed out high incidence, morbidity and mortality rate due to PPR in India. High economic loss in small ruminants is a major concern as it is mainly practiced by the small, marginal and landless farmers in India. The losses due to PPR might have reduced a major portion of their farm income among these rural people. To combat this threat comprehensive national programme have to be taken through combined efforts of local and national authorities along with continuous support and strengthening by international agencies.

How to cite this article : Roy, Rakesh (2018). Peste des Petits Ruminants in India: A review of economic losses. Agric. Update, 13(4): 463-469; DOI : 10.15740/HAS/AU/13.4/463-469. Copyright@2018: Hind Agri-Horticultural Society. 